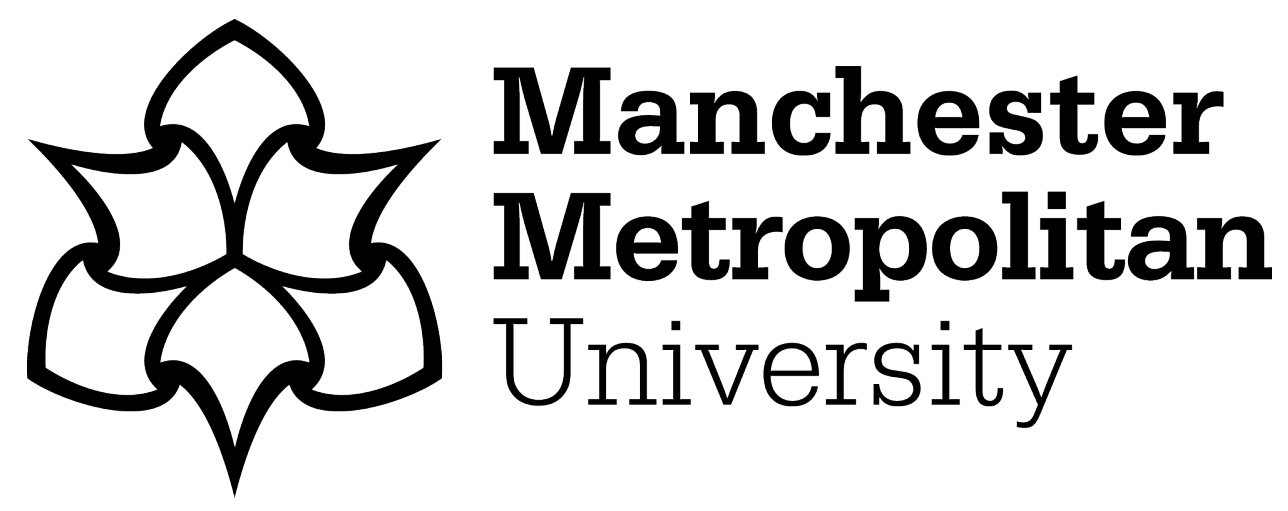

Butler, Jonathan ORCID logoORCID: https://orcid.org/0000-0002-13238611, Slate, Anthony, Todd, David, Airton, Douglas, Hardman, Michelle, Hickey, Niall, Scott, Kirsten and Venkatraman, Prabhuraj (2021) A traditional Ugandan Ficus natalensis bark cloth exhibits antimicrobial activity against Methicillin-Resistant Staphylococcus aureus. Journal of Applied Microbiology, 131 (1). pp. 2-10. ISSN 1364-5072

Downloaded from: https://e-space.mmu.ac.uk/626905/

Version: Accepted Version

Publisher: Wiley

DOI: https://doi.org/10.1111/jam.14945

Please cite the published version 
DR. JONATHAN ALEXANDER BUTLER (Orcid ID : 0000-0002-1323-8611)

DR. ANTHONY JOSEPH SLATE (Orcid ID : 0000-0002-7062-6901)

Article type : JAM - Original Article

\section{A traditional Ugandan Ficus natalensis bark cloth exhibits antimicrobial activity against Methicillin-Resistant Staphylococcus aureus.}

Jonathan A. Butler ${ }^{a^{*}}$, Anthony J. Slate ${ }^{b}$, David B. Todd ${ }^{a}$, Douglas Airton ${ }^{a}$, Michelle Hardman ${ }^{a}$, Niall A. Hickeya ${ }^{a}$ Kirsten Scottc ${ }^{c}$, and Prabhuraj D. Venkatraman ${ }^{d}$.

aFaculty of Science and Engineering, Manchester Metropolitan University, Chester Street, Manchester M1 5GD, UK.

bDepartment of Biology and Biochemistry, University of Bath, Claverton Down, Bath BA2 7AY, UK.

clstituto Marangoni, London E1 6PX, UK.

dSchool of Fashion, Faculty of Arts and Humanities, Manchester Metropolitan University, Manchester M15 6BG, UK.

*Author for correspondence: Dr Jonathan A. Butler, jonathan.butler@mmu.ac.uk

Faculty of Science and Engineering, Manchester Metropolitan University, Chester Street, Manchester M1 5GD, UK.

Running title: Antimicrobial activity of Ugandan bark cloth

This article has been accepted for publication and undergone full peer review but has not been through the copyediting, typesetting, pagination and proofreading process, which may lead to differences between this version and the Version of Record. Please cite this article as doi: 10.1111/JAM.14945

This article is protected by copyright. All rights reserved 


\section{Abstract}

Aims

Surgical site, soft tissue and wound infections are some of the most prominent causes of Healthcare associated infections (HCAls). Developing novel antimicrobial textiles and wound dressings may help alleviate the risk of developing HCAls. We aimed to determine the antimicrobial efficacy of natural Ugandan bark cloth derived exclusively from the Ficus natalensis tree.

\section{Methods and Results}

Antimicrobial contact and disc diffusion assays, coupled with time-kill kinetic assays demonstrated that bark cloth inhibited the growth of a clinically relevant Methicillinresistant Staphylococcus aureus (MRSA) strain and acted as a bactericidal agent causing a seven-log reduction in bacterial viability. Scanning electron microscopy was used to reveal morphological changes in the bacterial cell ultrastructure when exposed to bark cloth, which supported a proposed mechanism of antimicrobial activity.

\section{Conclusions}

The observed antimicrobial properties, combined with the physical characteristics elicited by bark cloth, suggest this product is ideally suited for wound and other skin care applications.

\section{Significance and Impact of the study}

This is the first report where a whole bark cloth product made by traditional methods has been employed as an antimicrobial fabric against MRSA. Bark cloth is a highly sustainable and renewable product and this study presents a major advance in the search for natural fabrics which could be deployed for healthcare applications.

Keywords: bark cloth; MRSA; antimicrobial; natural products; wound management; Ficus natalensis.

\section{Background}

Antimicrobial resistance is a major global issue (Blair et al. 2015). It is estimated that by 2050 , mortality rates associated with antimicrobial resistant infections will exceed 10 million people per annum, superseding cancer as the leading cause of global mortality (O'Neill 2016). Healhcare associated infections (HCAls) are a major cause of morbidity 
and mortality and it is estimated that between $7 \%$ and $10 \%$ of hospitalised patients will develop such an infection type (Danasekaran et al. 2014). Surgical site, soft tissue and wound infections are amongst the most common types of HCAI, with Methicillin-Resistant Staphylococcus aureus (MRSA) being a predominant cause of infection (Haque et al. 2018); another notable cause of wound infections is Pseudomonas aeruginosa, which is a prominent organism in the case of burns and immunocompromised patients (Church et al. 2006; Buhl et al. 2015; Cardona and Wilson 2015).

One method of reducing the transmission of pathogens in healthcare environments, whilst assisting the healing process and promoting localised antisepsis, is the development of antimicrobial textiles and wound dressings (Negut et al. 2018). Antimicrobial wound dressings vary considerably, with many employing metals and/or synthetic compounds as the active antimicrobial agents. These may include, basic wound contact fabric, films, fabric with metal/oxide-derivative coatings (Gao and Cranston 2008; Simončič and Klemenčič 2016), graphene-oxide (Zhao et al. 2013) and hydrocolloidbased dressings (Capanema et al. 2018). Some fabrics may incorporate synthetic antimicrobials such as quaternary ammonium compounds (Kang et al. 2016), biguanides (Kawabata and Taylor 2004) and guanidine (Li et al. 2018). Whilst, antibiotic impregnated wound dressings have also been researched extensively (Simões et al. 2018).

As most current antimicrobial fabrics involve the use of metals and/or synthetic compounds, using antimicrobial fabrics derived from natural sources may provide clinically useful alternatives, whilst promoting a more environmentally sustainable approach. One such emerging natural product is tree bark, where previous studies have demonstrated the antimicrobial activity of products extracted from Diplotropis ferruginea (Cerqueira et al. 2011) and other tropical and subtropical tree barks (Perez et al. 2001). A recent study highlighted the antimicrobial activity of crude solvent extracts from the leaves, bark and fruit of Ficus natalensis (wild fig tree) (Awolola et al. 2017), part of the Moraceae tree family which are geographically distributed in southern and eastern Africa.

Throughout the present study the antimicrobial efficacy of bark from $F$. natalensis in the form of bark cloth (without an extraction process) was determined. Bark cloth is a nonwoven fibrous structure harvested from $F$. natalensis tree bark by the Baganda people of the Southern Ugandan community since at least the 13th Century. Historically, it has been used in clothing for ceremonial occasions by the Baganda community 
(Nakazibwe 2005). The making of bark cloth has been passed on through many generations and is a highly skilful activity that reflects the identity of the community. UNESCO has recognised it as an 'intangible cultural heritage of humanity' (UNESCO 2008), emphasising the rationale to preserve the knowledge, skills, and the art of making bark cloth. Bark cloth harvesting occurs annually during the rainy season without damaging the tree, as the trunk is wrapped in banana leaves after harvesting to prevent dehydration (Rwawiire et al. 2013). The trees grow without the need for any fertilisers or pesticides and are frequently used in local agro-forestry systems to provide shade to other crops and are reputed locally to add nutrients to the soil. Figure 1 (A-D) illustrates the characteristic bark cloth making process by artisans and the Bukomansimbi Organic Tree Farmers Association (BOTFA) inspecting the bark cloth sheets, where the images were obtained during field work in 2014 and 2019 (Scott 2019).

Other related research on bark cloth reported the thermo-physiological properties of the bark cloth, where it was observed to have lower thermal absorptivity than cotton fibre and higher moisture absorption (Rwawiire and Tomkova 2013). In addition, bark cloth based green epoxy composites showed sufficient tensile strength suitable for automotive panels (Rwawiire et al. 2015). Natural Ugandan bark cloth has a stiff texture, is porous, varies in thickness $(0.672 \mathrm{~mm} \pm 0.05)$ with random fibre arrangement, but most areas show diagonal fabric grain (Fig. 2A) (Venkatraman et al. 2020). In the same study, surface morphological assessment using Energy Dispersive Spectroscopy (EDX) showed traces of calcium and sodium. Based on this comprehensive analysis, it was recommended as a sustainable material for developing small scale, niche fashion collections, which could preserve this endangered art of making bark cloth (Venkatraman et al. 2020).

In the present study, we aimed to examine the feasibility of using bark cloth as an antimicrobial fabric for clinical use within wound care management. This was achieved using a combination of antimicrobial susceptibility assays coupled with scanning electron microscopy to elucidate the nature of the observed antimicrobial effects. 


\section{Materials and methods}

\section{Bacterial strains}

Methicillin-resistant Staphylococcus aureus strain USA300 (ST8) JE2 (Fey et al. 2013) and Pseudomonas aeruginosa strain PAO1 (Holloway 1955) were cultured using Mueller Hinton $(\mathrm{MH})$ agar or broth (Oxoid, UK) and incubated under aerobic conditions at $37^{\circ} \mathrm{C}$ for $24 \mathrm{~h}$, with agitation (150 rpm) for broth cultures.

\section{Bark cloth preparation}

Bark cloth was made by local artisans using traditional techniques and kindly supplied by Dr K. Scott (Istituto Marangoni, London UK). Briefly, bark from the $F$. natalensis was harvested, pressed and shaped with stretching and allowed to dry naturally under sunlight. To determine the durability of bark cloth, four samples each measuring $30 \times 21 \mathrm{~cm}$ (Fig. 3) were washed and rinsed with ECE detergent (phosphate powder with no optical brighteners used in British Standard wash tests recommended for textiles) in a container with $5 \mathrm{~L}$ of cold water. The fabric was submerged ten times with no wringing. The bark cloth was then rinsed in another container of water $(5 \mathrm{~L})$ to remove any detergent and dried at room temperature for $24 \mathrm{~h}$. Prior to microbiological experimentation, the fabric was exposed to ultraviolet light for $1 \mathrm{~h}$ with frequent rotation.

\section{Antimicrobial susceptibility \\ Contact assay}

Contact assays were performed in accordance with a modified Deutsches Institut für Normung (DIN) 58940-3 agar diffusion standard method (Wiegand et al., 2015). Briefly, $6 \mathrm{~mm}$ diameter circular discs of both washed and unwashed bark cloth were added to agar plates pre-inoculated with $100 \mu \mathrm{L}$ of $S$. aureus strain USA300 or $P$. aeruginosa strain PAO1, which were adjusted to an Optical Density of $0.5( \pm 0.05)$ at 600 $\mathrm{nm}\left(\mathrm{OD}_{600}\right)$. Aliquots of $10 \mu \mathrm{L}$ phosphate buffered saline (PBS) were added to fabric disc samples to facilitate diffusion. Inoculated agar plates were incubated for $24 \mathrm{~h}$ at $37{ }^{\circ} \mathrm{C}$ under aerobic conditions and the size of bacterial growth inhibitory zones were determined using a digital calliper gauge. Filter paper discs $(6 \mathrm{~mm}$ diameter; Whatman, Merck UK) with $10 \mu \mathrm{L}$ PBS were included as a control. All assays were performed in triplicate with biological replicates $(n=3)$.

\section{Antimicrobial extraction and disk diffusion assay}


Antimicrobial susceptibility was determined using a modified EUCAST disk diffusion method (Matuschek et al., 2015). Briefly, unwashed and washed bark cloth samples (surface area: $1 \mathrm{~cm}^{2}$ ) were exposed to $500 \mu \mathrm{L}$ analytical grade $95 \%$ ethanol, PBS or dimethylsulfoxide (DMSO) for $24 \mathrm{~h}$. Supernatants were harvested and $10 \mu \mathrm{L}$ of each were added to $6 \mathrm{~mm}$ diameter circular filter paper discs (Whatman, Merck UK) on the surface of $\mathrm{MH}$ agar which was pre-inoculated with $100 \mu \mathrm{L}$ of $S$. aureus strain USA300 at an $\mathrm{OD}_{600}$ of 0.5 ( \pm 0.05$)$. Plates were incubated for $24 \mathrm{~h}$ at $37^{\circ} \mathrm{C}$ and bacterial growth inhibitory zones were measured. Solvent only controls were included for comparison and assays were performed in triplicate with biological replicates $(n=3)$.

\section{Time-kill kinetic assays}

An overnight culture of $S$. aureus strain USA300 was adjusted to an $O_{600}$ of 0.0025 (approximately $1 \times 10^{7}$ Colony Forming Units (CFU) $\mathrm{mL}^{-1}$ ) in $\mathrm{MH}$ broth and $1 \mathrm{~cm}^{2}$ unwashed bark cloth samples were added. Cultures were incubated for $24 \mathrm{~h}$ at $37{ }^{\circ} \mathrm{C}$ with agitation and bacterial viability was determined at $0 \mathrm{~h}, 2 \mathrm{~h}, 4 \mathrm{~h}, 6 \mathrm{~h}$ and $24 \mathrm{~h}$ (Miles et al. 1938; Hickey et al. 2019). Control cultures excluding bark cloth were included and bark cloth was also incubated in $\mathrm{MH}$ broth without bacterial inoculation to confirm sterility. All assays were performed in biological triplicates $(n=3)$.

\section{Scanning Electron Microscopy (SEM)}

After $24 \mathrm{~h}$ incubation following the time-kill kinetic assay, bark cloth samples were fixed in $4 \% \mathrm{v} / \mathrm{v}$ glutaraldehyde for $24 \mathrm{~h}$ at $4{ }^{\circ} \mathrm{C}$. Fixed samples were rinsed with sterile deionised water and subjected to an ethanol gradient from $10 \%$ to $30 \%, 50 \%, 70 \%, 90 \%$ and $100 \%$ v/v absolute ethanol (Liauw et al. 2019). Samples were dried by desiccation over $24 \mathrm{~h}$ and were sputter coated with gold (Polaron, UK) for $30 \mathrm{~s}$ (parameters: power $5 \mathrm{~mA}, 30 \mathrm{~s}, 800 \mathrm{~V}$, vacuum 0.09 mbar, argon gas) prior to imaging using a JEOL JSM 5600LV scanning electron microscope.

\section{Statistical analysis}

One or Two-way ANOVA statistical tests with Tukey's tests for post hoc analysis were performed using GraphPad Prism version 8.4.2 (GraphPad Software, USA).

\section{Results}

Bark cloth directly inhibited growth of S. aureus strain USA300 
Prior to use, bark cloth was washed (Fig. 3A and B) to determine the durability of the fabric and whether any observed antimicrobial activity was due to loosely incorporated residues. Washing resulted in a dark coloured elution (Fig. 3C), which resembled the distinctive bark cloth colour and suggested evidence of residual leachate. Bark cloth was then used in a surface contact agar diffusion assay and demonstrated antimicrobial activity against Methicillin-resistant S. aureus strain USA300. Zones of bacterial growth inhibition were observed with both unwashed and washed derivatives of bark cloth with mean diameters of $7.58 \mathrm{~mm}$ and $7.36 \mathrm{~mm}$ respectively (Fig. 4, black and shaded bars). One-way ANOVA with a Tukey's test for post hoc analysis demonstrated that there was no significant difference between the diameters of the inhibitory zones produced by either bark cloth derivative $(P>0.05)$, in contrast to the filter paper disc control $(P \leq 0.001)$ where no growth inhibition was observed (Fig. 4, no bar). No evidence of antimicrobial activity was observed when bark cloth was exposed to $P$. aeruginosa strain PAO1 (data not shown).

\section{Solvent extracts from bark cloth inhibited growth of $S$. aureus strain USA300}

Extracts from both unwashed and washed bark cloth were produced by exposure to PBS, ethanol (95\%) or DMSO and $10 \mu \mathrm{L}$ of supernatant was added to filter paper discs. These were positioned onto $\mathrm{MH}$ agar, which was pre-inoculated with $S$. aureus strain USA300. After $24 \mathrm{~h}$ incubation, DMSO extracted supernatant from both unwashed and washed bark cloth significantly inhibited bacterial growth $(P \leq 0.001)$ and produced inhibitory zones of 7.40 and $7.14 \mathrm{~mm}$ respectively (Fig. 5, black and shaded bars), compared to $0 \mathrm{~mm}$ for the DMSO solvent alone (Fig. 5, no bar). The DMSO extract from unwashed bark demonstrated significantly greater antimicrobial activity than the extract from the washed cloth $(P \leq 0.05)$. Ethanol and PBS extracts had no observable effect on the growth of $S$. aureus strain USA300 (data not shown).

\section{Bark cloth significantly reduced the viability of S. aureus strain USA300}

Unwashed bark cloth was incubated with $S$. aureus strain USA300 and bacterial viability was determined over a $24 \mathrm{~h}$ period. After $4 \mathrm{~h}$ incubation, a significant one-log reduction in viability was observed $(P \leq 0.01)$ in bacteria exposed to bark cloth compared to the unexposed control (Fig. 6, dashed compared to solid line). After $24 \mathrm{~h}$, bacterial viability decreased by approximately four logs when compared to the starting culture viability at $0 \mathrm{~h}\left(10^{7}\right.$ to $\left.10^{3} \mathrm{CFU} \mathrm{mL} \mathrm{m}^{-1}\right)$. However, when compared to the unexposed 
bacterial culture control, at $24 \mathrm{~h}$ there was a significant $(P \leq 0.0001)$ seven-log reduction (1010 to $10^{3} \mathrm{CFU} \mathrm{mL}^{-1}$ ) in bacterial viability in the culture exposed to bark cloth. No bacterial growth was observed when bark cloth was incubated in $\mathrm{MH}$ broth without bacterial inoculation which demonstrated the sterility of the cloth (data not shown).

\section{Bark cloth exposure resulted in morphological changes to the cell ultrastructure of}

\section{S. aureus strain USA300}

Scanning electron microscopy (SEM) was used to examine the effects of exposure to bark cloth on S. aureus strain USA300 and to help elucidate the mechanisms of antimicrobial activity. Bark cloth samples from the time-kill kinetics assay were subjected to visual analysis by SEM after $24 \mathrm{~h}$. Bacterial attachment and biofilm formation was visible on the fibrous structure of the bark cloth (Fig. 7A) compared to the un-inoculated control (Fig. 7C). Distinct morphological changes in the bacterial cellular ultrastructure, including invaginations, perforations, pits, and holes were observed in $S$. aureus strain USA300 cells which were exposed to bark cloth (Fig. 7A). Such morphological changes were indicative of antimicrobial activity against the cell ultrastructure when compared to unexposed bacterial cells (Fig. 7B), which had intact cellular features.

\section{Discussion}

As society approaches a post antibiotic era, new antimicrobial interventions are urgently needed, both as treatment options and infection prevention strategies. Wound infections caused by multidrug-resistant bacterial pathogens are a major cause of morbidity and mortality, and result in significant socio-economic burdens to the healthcare system (Leaper et al. 2004). Current wound dressing technology predominantly focuses on utilising synthetic antimicrobial agents to assist with clinical wound management. However, natural products from floral and arboreal origins have been used in medicinal applications for centuries (Mahady et al. 2008) and there is an ever-increasing need for greener, more sustainable healthcare technologies.

Antimicrobial compounds derived from extracts of flora, herbs, leaves and trees are widely reported and reviewed elsewhere (Cowan 1999; Khameneh et al. 2019). Many studies rely on solvent extraction to identify key antimicrobial mediators and rarely use whole products for antimicrobial applications. Here, we reported the first example of an unmodified, natural fabric product derived from the tree bark of $F$. natalensis, which could 
be used as an antimicrobial textile or wound dressing. The bark cloth inhibited growth of a well-characterised MRSA clinical isolate and this activity was retained despite washing the fabric. One of the biggest challenges for antimicrobial fabric production is ensuring that activity is retained after standard washing procedures; therefore the bark cloth presents an interesting material for further research into potential commercial fabric uses.

For clinical wound dressing applications, it is important that antimicrobial activity is retained for a designated time, such as the period between dressing and reapplication (Negut et al. 2018). Antimicrobial releasing properties are also a factor when considering novel wound dressing development, in order to ensure local dissemination of the active compound(s). A 99\% reduction in bacterial viability after $4 \mathrm{~h}$ was observed when bark cloth was exposed to MRSA during time-kill kinetic assays, compared to the unexposed bacterial control strain. After $24 \mathrm{~h}$, this increased to a $99.99999 \%$ (seven-log) reduction in bacterial viability. Such potent and long lasting antimicrobial activity would be highly beneficial for use within wound care management. The time-kill kinetics assay demonstrated that the active antimicrobial compound(s) might have diffused from the bark cloth, but visualisation of the fabric using SEM showed biofilms of cells with significant morphological changes in cellular ultrastructure. Bacterial cells became irregular in shape, with invaginations, holes and perforations, which is consistent with bacterial cytoplasmic membrane damage (Côté et al. 2019). Furthermore, there was clear visual evidence of cytoplasmic leakage that is consistent with perturbation of the bacterial cytoplasmic membrane (Otto et al. 2010), which further demonstrated the mechanism of antimicrobial activity of the bark cloth (and associated active antimicrobial compound(s)). Combined, these indicated that bark cloth has both slow releasing and contact killing antibacterial properties, which are highly desirable characteristics of novel wound dressings.

The preferable characteristics of an ideal wound dressing include, control of moisture around the wound, good gaseous transmission, elimination of excess exudates, antimicrobial activity, biocompatibility, reduced wound surface necrosis, mechanical protection, easily exchangeable, biodegradable and cost-effective (Rezvani Ghomi et al. 2019). The bark cloth utilised throughout this study has previously demonstrated good porosity (Fig. 2; Venkatraman et al. 2020), which would facilitate gaseous exchange between the wound site and environment, and potentially self-disinfecting against 
contamination with Gram-positive $S$. aureus bacteria, which are also key characteristics of ideal wound dressings (Dhivya et al. 2015).

The active antimicrobial compound(s) from bark cloth remains to be determined. However, a study conducted previously by Venkatraman et al. (2020) revealed the elemental composition of the $F$. natalensis bark cloth, where elements such as chlorine, calcium and magnesium were reported on the surface of the bark cloth. All three of these elements have known antimicrobial activity, in particular in ionic forms due to their binding affinity for functional groups (i.e. thiol groups) in bacterial cells (Stiefel et al. 2015; Slate et al. 2019). Chlorine affects bacterial cell viability by chlorinating the lipid protein in the cell wall, which results in macromolecule leakage from the cell (Kim et al. 2008). Calcium $\left(\mathrm{Ca}^{2+}\right)$ and magnesium $\left(\mathrm{Mg}^{2+}\right)$ ions are physiologically essential to almost all living organisms (Cutinelli and Galdiero 1967). However, such ions can bind with cardiolipin, a major lipid component in the $S$. aureus cytoplasmic membrane, where binding complexes form a negative curvature which can result in a variety of membrane-destabilisation processes and subsequent cell death (Short and White 1971; Rand et al. 1972; Schmidt et al. 2011; Tsai et al. 2011; Xie and Yang 2016). This could explain the observed antimicrobial activity against MRSA and morphological changes in bacterial cell ultrastructure. Interestingly however, when washed, the bark cloth retained antimicrobial activity, therefore it is likely that combinations of antimicrobial factors are responsible.

Other potential antimicrobial compounds within the bark cloth may include triterpenoids and quinones such as tectoquinone, which were previously identified from crude F. natalensis extracts by vacuum column chromatography (Awolola et al. 2017). However, in this study, extracts from other components of the tree, such as the leaves and fruit were more effective antimicrobial and anti-biofilm agents than those isolated from the bark. These compounds demonstrated broad-spectrum antimicrobial activity against both Gram-positive and negative bacteria (Awolola et al. 2017), but required a solvent extraction process. In contrast, in our study the unmodified and natural bark cloth was bactericidal against the Gram-positive S. aureus strain USA300 and was not active against the Gram-negative $P$. aeruginosa. However, this suggests that combining other components of $F$. natalensis into the bark cloth may produce a final product with enhanced broad-spectrum activity. 
To the authors' knowledge, this is the first report where an unmodified, sustainable natural whole bark cloth made by traditional methods has been employed as an antimicrobial fabric against MRSA. The potential clinical and commercial use of bark cloth derived exclusively from $F$. natalensis represents a significant advance in the search for novel antimicrobial products which could help prevent healthcare associated and wound infections. Isolation, purification and identification of the active antimicrobial compound derived from bark cloth may help further understand the efficacy and mechanisms of antimicrobial activity. Furthermore, understanding the immunological role of bark cloth in mediating the healing process would also provide a useful insight into the potential for use in clinical applications. Overall, this study suggests the current antimicrobial properties and physical characteristics of natural bark cloth are ideally suited for use in wound care management.

\section{Acknowledgements}

The authors wish to acknowledge technical support provided by Hayley Andrews (Manchester Metropolitan University, UK) for assistance with Scanning Electron Microscopy and Derek Hebdon (Manchester Metropolitan University, UK) for preparing bark cloth samples and textile evaluation. We also acknowledge Dr. Christopher Liauw for providing useful discussions regarding the physical properties of bark cloth, Jonathan Biddulph for assistance with fabric manipulation and Mark Pittendrigh for IT assistance.

\section{Funding}

This research did not receive any specific grant from funding agencies in the public, commercial, or not-for-profit sectors.

\section{Declaration of competing interest}

The authors report no conflict of interest.

\section{References}

Awolola, G.V., Chenia, H., Baijnath, H. and NKoorbanally, N.A. (2017) Anti-adhesion potential of non-polar compounds and extracts from $H$. natalensis. Rev Bras Farmacogn 27(5), 599-602. 
Blair, J.M., Webber, M.A., Baylay, A.J., Ogbolu, D.O. and Piddock, L.J. (2015) Molecular mechanisms of antibiotic resistance. Nat Rev Microbiol 13(1), 42-51.

Buhl, M., Peter, S. and Willmann, M. (2015) Prevalence and risk factors associated with colonization and infection of extensively drug-resistant Pseudomonas aeruginosa: a systematic review. Expert Rev Anti-Infect Ther 13(9), 1159-1170.

Capanema, N.S.V., Mansur, A.A.P., Carvalho, S.M., Mansur, L.L., Ramos, C.P., Lage, A.P. and Mansur, H.S. (2018) Physicochemical properties and antimicrobial activity of biocompatible carboxymethylcellulose-silver nanoparticle hybrids for wound dressing and epidermal repair. J Appl Polym Sci 135, 45812.

Cardona, A.F. and Wilson, S.E. (2015) Skin and soft-tissue infections: a critical review and the role of telavancin in their treatment. Clin Infect Dis 15, 61.

Cerqueira, G., Rocha, N., Almeida, J., de Freitas, A., Lima, E., Filho, J., de Freitas, R. and Diniz, M.M. (2011) Antimicrobial activity of the extract of stem bark of Diplotropis ferruginea benth. J Young Pharm 3(4), 284-286.

Church, D., Elsayed, S., Reid, O., Winston, B. and Lindsay, R. (2006) Burn wound infections. Clin Microbiol Rev 19(2), 403-434.

Côté H., Pichette A., Simard, F., Ouellette, M-E., Ripoll, L., Mihoub, M., Grimard, D. and Legault, J. (2019) Balsacone C, A New Antibiotic Targeting Bacterial Cell Membranes Inhibits Clinical Isolates of Methicillin-Resistant Staphylococcus aureus (MRSA) Without Inducing Resistance. Front Microbiol 10, 2341.

Cowan, M.M. (1999) Plant products as antimicrobial agents. Clin Microbiol Rev 12(4), 564-582.

Cutinelli, C. and Galdiero, F. (1967) lon-binding properties of the cell wall of Staphylococcus aureus. J Bacteriol 93(6), 2022.

Danasekaran, R., Mani, G. and Annadurai, K. (2014) Prevention of healthcare-associated infections: protecting patients, saving lives. Int $J$ of Community Med Public Health 1(1), 67-68

Dhivya, S., Padma V.V. and Santhini, E. (2015) Wound dressings - a review. Biomedicine (Taipei). 5(4), 22.

Fey, P.D., Endres, J.L., Yajjala, V.K., Widhelm, T.J., Boissy, R.J., Bose, J.L. and Bayles, K.W. (2013) A genetic resource for rapid and comprehensive phenotype screening of nonessential Staphylococcus aureus genes. mBio 4(1), e00537-12. 
Gao, Y. and Cranston, R. (2008) Recent Advances in Antimicrobial Treatments of Textiles. Text Res J 78(1), 60-72.

Haque, M., Sartelli, M., McKimm, J. and Abu Bakar, M. (2018) Health care-associated infections - an overview. Infect Drug Resist 11, 2321-2333.

Hickey, N.A., Whitehead, K.A., Shalamanova, L., Butler, J.A. and Taylor, R.L. (2019) A novel microbiological medium for the growth of periodontitis associated pathogens. $J$ Microbiol Methods 163, 105647

Holloway, B.W. (1955) Genetic recombination in Pseudomonas aeruginosa. J Gen Microbiol 13, 572-581

Kang, C.K., Kim, S.S., Kim, S., Lee, J., Lee, J-H., Roh, C. and Lee, J. (2016) Antibacterial cotton fibers treated with silver nanoparticles and quaternary ammonium salts. Carbohydr Polym 151, 1012-1018.

Kawabata, A. and Taylor, J.A. (2004) Effect of reactive dyes upon the uptake and antibacterial action of poly(hexamethylene biguanide) on cotton. Part 1: Effect of bis(monochlorotriazinyl) dyes. Color Technol 120, 213-219.

Khameneh, B., Iranshahy, M., Soheili, V. and Bazzaz, B.S.F. (2019) Review on plant antimicrobials: a mechanistic viewpoint. Antimicrob Resist Infect Control 8, 118.

Kim, J., Pitts, B., Stewart, P.S., Camper, A. and Yoon, J. (2008) Comparison of the antimicrobial effects of chlorine, silver ion, and tobramycin on biofilm. Antimicrob Agents Chemother 52(4), 1446-1453.

Leaper, D., van Goor, H., Reilly, J., Petrosillo, N., Geiss, H., Torres, A. and Berger, A. (2004) Surgical site infection - a European perspective of incidence and economic burden. Int Wound J 1, 247-273.

Li, Z., Chen, J., Cao, W., Wei, D., Zheng, A. and Guan, Y. (2018) Permanent antimicrobial cotton fabrics obtained by surface treatment with modified guanidine. Carbohydr Polym 180, 192-199.

Liauw, C.M., Slate, A.J., Butler, J.A., Wilson-Nieuwenhuis, J.S.T., Deisenroth, T., Preuss, A., Verran, J. and Whitehead, K.A. (2020) The Effect of Surface Hydrophobicity on the Attachment of Fungal Conidia to Substrates of Polyvinyl Acetate and Polyvinyl Alcohol. $J$ Polym Environ 28, 1450-1464.

Mahady, G.B., Huang, Y., Doyle, B.J. and Locklear, T. (2008) Natural products as antibacterial agents. Stud Nat Prod Chem 35, 423-444. 
Matuschek, E., Brown, D.F. and Kahlmeter, G. (2014) Development of the EUCAST disk diffusion antimicrobial susceptibility testing method and its implementation in routine microbiology laboratories. Clin Microbiol Infect 20(4), O255-O266.

Miles, A.A., Misra, S.S. and Irwin, J.O. (1938) The estimation of the bactericidal power of the blood. Epidemiol Infect 38(6), 732-749.

Nakazibwe, V. (2005) Barkcloth of the Baganda People of Southern Uganda: A Record of Continuity and Change from the late $20^{\text {th }}$ Century to the early $21^{\text {st }}$ Century, Doctoral Thesis, Middlesex University, available from: http://ethos.bl.uk/SearchResults.do [accessed 19.02.17]

Negut, I., Grumezescu, V. and Grumezescu, A.M. (2018) Treatment Strategies for Infected Wounds. Molecules 23(9), 2392.

O'Neill, J. (2016) Tackling drug-resistant infections globally: final report and recommendations. London: Review on Antimicrobial Resistance.

Otto, C.C., Cunningham, T.M., Hansen, M.R. and Haydel, S.E. (2010) Effects of antibacterial mineral leachates on the cellular ultrastructure, morphology, and membrane integrity of Escherichia coli and methicillin-resistant Staphylococcus aureus. Ann Clin Microbiol Antimicrob 9, 26

Pérez, G.S., Zavala, S.M.A., Arias, G. L., Pérez, G.C. and Pérez, G.R.M. (2001) Antimicrobial study of bark from five tree species. Phytother Res 15(4), 356-359.

Rand, R.P. and Sengupta, S. (1972) Cardiolipin forms hexagonal structures with divalent cations. BBA-Biomembranes 255(2), 484-492.

Rezvani Ghomi, E., Khalili, S., Nouri Khorasani, S., Esmaeely Neisiany, R. and Ramakrishna, S. (2019) Wound dressings: Current advances and future directions. J Appl Polym Sci 136(27), 47738.

Rwawiire, S. and Tomkova, B. (2013) Thermo-physiological and Comfort Properties of Ugandan Barkcloth from Ficus natalensis. J Tex / 105(6), 648-653.

Rwawiire, S., Luggya, G.W. and Tomkova B. (2013) Morphology, thermal and mechanical characterisation of bark cloth from Ficus natalensis, ISRN Text 2013, 1-8

Rwawiire, S., Tomkova, B., Militky, J., Jabbar, A. and Kale, B. (2015) Development of a biocomposite based on green epoxy polymer and natural cellulose fabric (bark cloth) for automotive instrument panel applications. Compos Part B-Eng 81,149-157. 
Schmidt, N.W., Mishra, A., Lai, G.H., Davis, M., Sanders, L.K., Tran, D., Garcia, A., Tai, K.P., McCray Jr, P.B., Ouellette, A.J. and Selsted, M.E. (2011) Criterion for amino acid composition of defensins and antimicrobial peptides based on geometry of membrane destabilization. J Am Chem Soc 133(17), 6720-6727.

Scott K. (2020) Future Luxury: Fashioning Wellbeing Through Holistic Design. In: Cantista I., Sádaba T. (eds) Understanding Luxury Fashion. Palgrave Macmillan.

Short, S.A. and White, D.C. (1971) Metabolism of phosphatidylglycerol, lysylphosphatidylglycerol, and cardiolipin of Staphylococcus aureus. J Bacteriol 108(1), 219-226.

Simões, D., Miguel, S.P., Ribeiro, M.P., Coutinho, P., Mendonça, A.G. and Correia, I.J. (2018) Recent advances on antimicrobial wound dressing: A review. Eur $J$ Pharm Biopharm 127, 130-141.

Simončič, B. and Klemenčič, D. (2016) Preparation and performance of silver as an antimicrobial agent for textiles: A review. Text Res J 86(2), 210-223.

Slate, A.J., Shalamanova, L., Akhidime, I.D. and Whitehead, K.A. (2019) Rhenium and yttrium ions as antimicrobial agents against multidrug resistant Klebsiella pneumoniae and Acinetobacter baumannii biofilms. Lett Appl Microbiol 69(3),168-174.

Stiefel, P., Schmidt-Emrich, S., Maniura-Weber, K. and Ren, Q. (2015) Critical aspects of using bacterial cell viability assays with the fluorophores SYTO9 and propidium iodide. BMC Microbiol 15(1), 36.

Tsai, M., Ohniwa, R.L., Kato, Y., Takeshita, S.L., Ohta, T., Saito, S., Hayashi, H. and Morikawa, K. (2011) Staphylococcus aureus requires cardiolipin for survival under conditions of high salinity. BMC Microbiol 11(1), 13.

UNESCO (2008) A report on the revitalisation of bark cloth making in Uganda UNESCO/Japanese funds-in-trust Project.

Venkatraman, P.D., Scott, K. and Liauw, C. (2020) 'Environmentally friendly and sustainable bark cloth for garment applications: Evaluation of fabric properties and apparel development'. Sustainable Mater Technol 23, e00136.

Wiegand, C., Abel, M., Ruth, P., Elsner, P. and Hipler, U.C. (2015) In vitro assessment of the antimicrobial activity of wound dressings: influence of the test method selected and impact of the pH. J Mater Sci Mater Med 26(1), 5343-5349. 
Xie, Y. and Yang, L. (2016) Calcium and magnesium ions are membrane-active against stationary-phase staphylococcus aureus with high specificity. Sci Rep 6(1), 1-8.

Zhao, J., Deng, B., Lv, M., Li, J., Zhang, Y., Jiang, H., Peng, C., Li, J., Shi, J., Huang, Q. and Fan, C. (2013) Graphene oxide-based antibacterial cotton fabrics. Adv Healthcare Mater 2(9), 1259-66.

\section{Author contributions}

J.A.B. devised the project, performed laboratory experimentation and wrote the manuscript. A.J.S., N.A.H. and P.D.V. contributed to experimental design, analysis and drafting of the manuscript. D.B.T., D.A. and M.H. substantially contributed to the design and acquisition of data. K.S. provided experimental materials and details/figures of the fabric production process. All authors discussed the results and contributed to the final drafting and revising of the manuscript. All authors approved the final submitted version.

\section{Figures}

Figure 1. Stages of bark cloth production including harvesting $(A)$, fabrication $(B)$, large sheets dried under sunlight (C) and quality inspection by Bukomansimbi Organic Tree Farmers Association representatives (D).

Figure 2. Analysis of bark cloth demonstrated the direction of the fabric grain (A, white lines) and Scanning Electron Microscopy revealed the fibrous nature of the cloth $(B)$.

Figure 3. Bark cloth before $(A)$ and after washing (B). Coloured leachates showing a characteristic bark cloth terracotta colour were observed in both the washing and rinsing stages $(\mathrm{C})$.

Figure 4. Contact assays demonstrated the antimicrobial activity of unwashed bark cloth (black bar) and washed (shaded bar) against S. aureus strain USA300. There was no significant difference in the size of inhibitory zones produced between these samples, whereas both produced significantly larger inhibitory zones compared the filter paper control (no bar). $n=3$; Error bars represent SEM; ${ }^{* * * *}$ denotes $\mathrm{P} \leq 0.0001$. 
Figure 5. Disc diffusion assays demonstrated the antimicrobial activity of DMSO solvent extracts from unwashed bark cloth (black bar) and washed (shaded bar) against $S$. aureus strain USA300. Extracts from unwashed bark cloth produced significantly larger zones of inhibition compared to extracts from pre-washed fabric. Both produced significantly larger zones compared to the DMSO solvent control (no bar). $n=3$; Error bars represent SEM; * denotes $\mathrm{P} \leq 0.05$ and ${ }^{* * * *} \mathrm{P} \leq 0.0001$.

Figure 6. Time-kill kinetic assay of $S$. aureus strain USA300 after $24 \mathrm{~h}$ after constant exposure to bark cloth ( $\bullet \bullet \cdot$, dashed line) compared to S. aureus strain USA300 alone ( $\rightarrow$, solid line). $n=3$; Error bars represent SEM (not visible); ${ }^{* *}$ denotes $\mathrm{P} \leq 0.01$ and ${ }^{* * *}$ $P \leq 0.0001$.

Figure 7. Scanning Electron Microscopy analysis of (A) S. aureus strain USA300 in contact with bark fabric, (B) unexposed S. aureus strain USA300 and (C) un-inoculated bark fabric. Micrographs are representative examples. Scale bars are shown in $\mu \mathrm{m}$. 


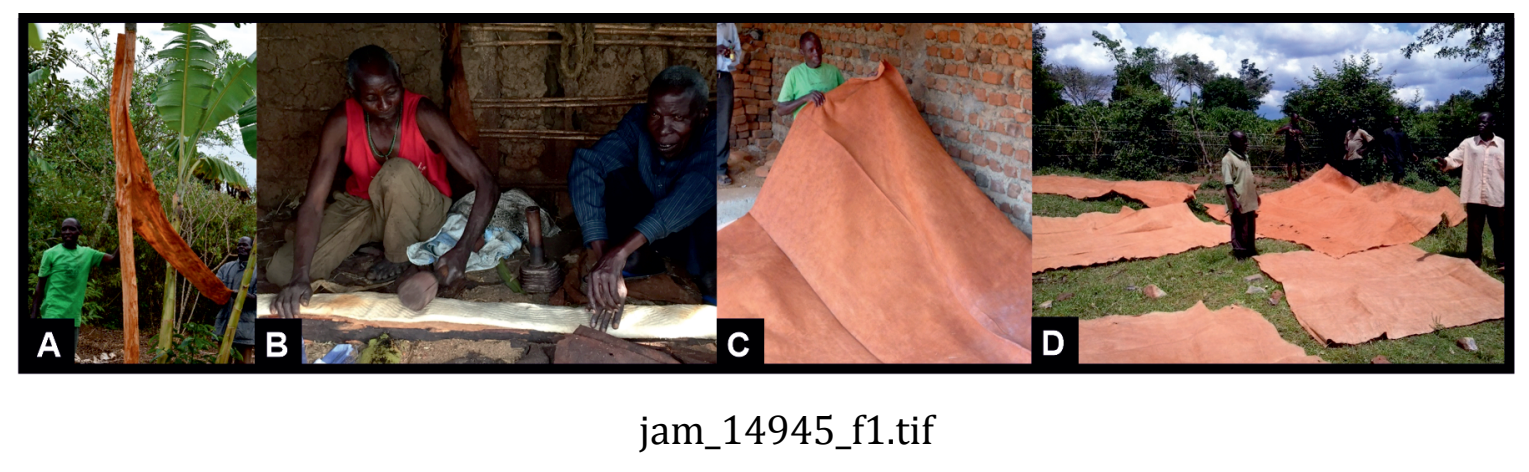

This article is protected by copyright. All rights reserved 


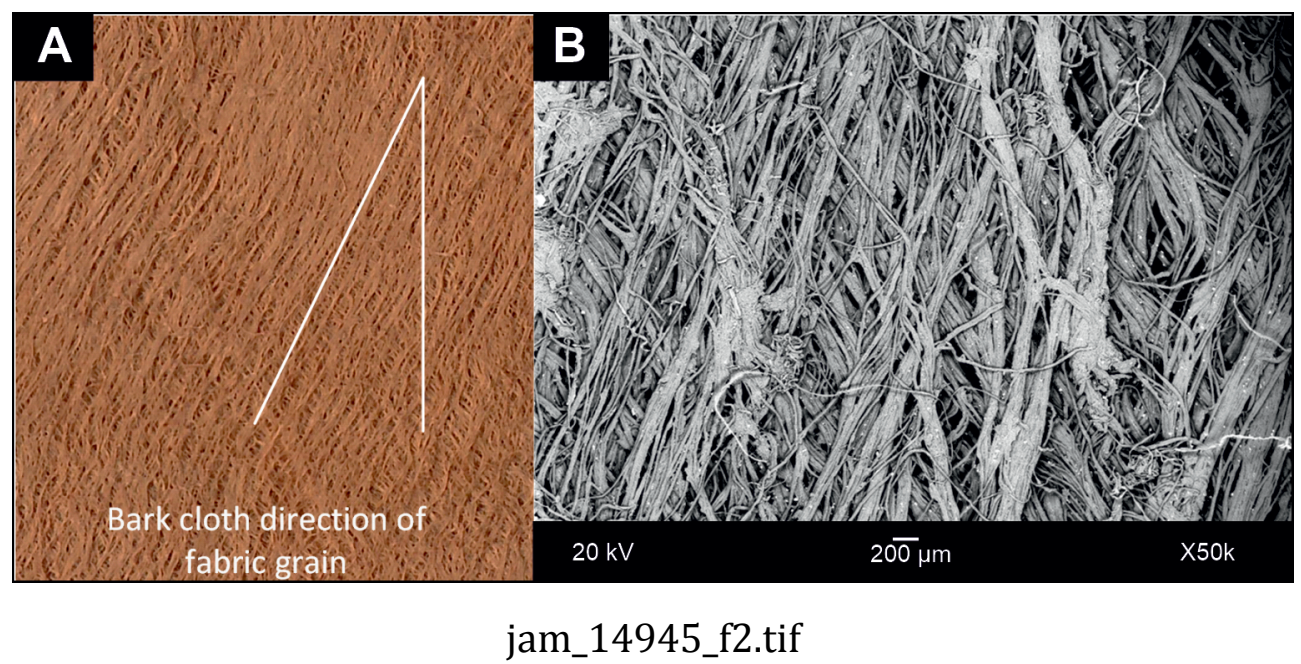

This article is protected by copyright. All rights reserved 


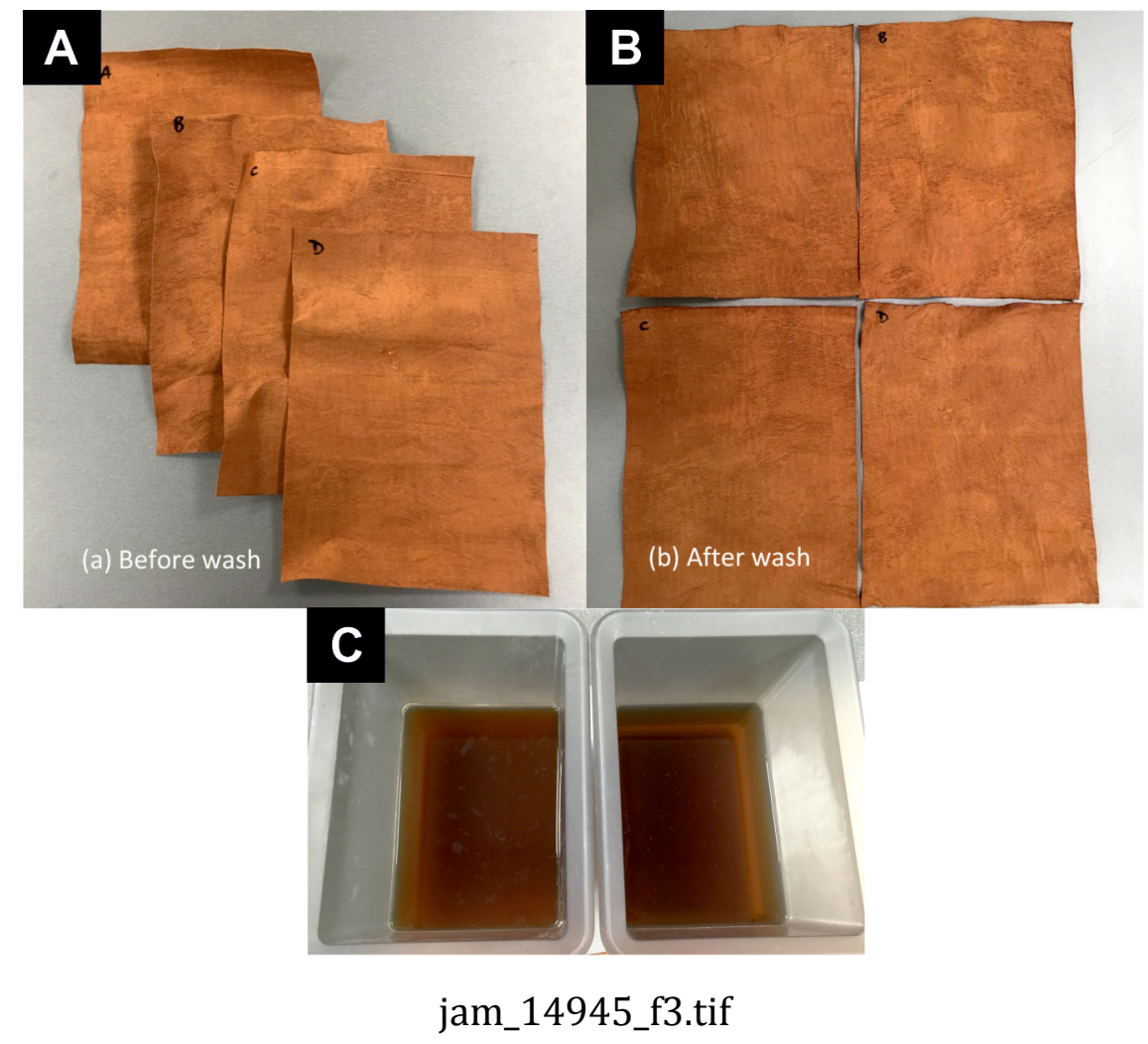

This article is protected by copyright. All rights reserved 
$* * * *$

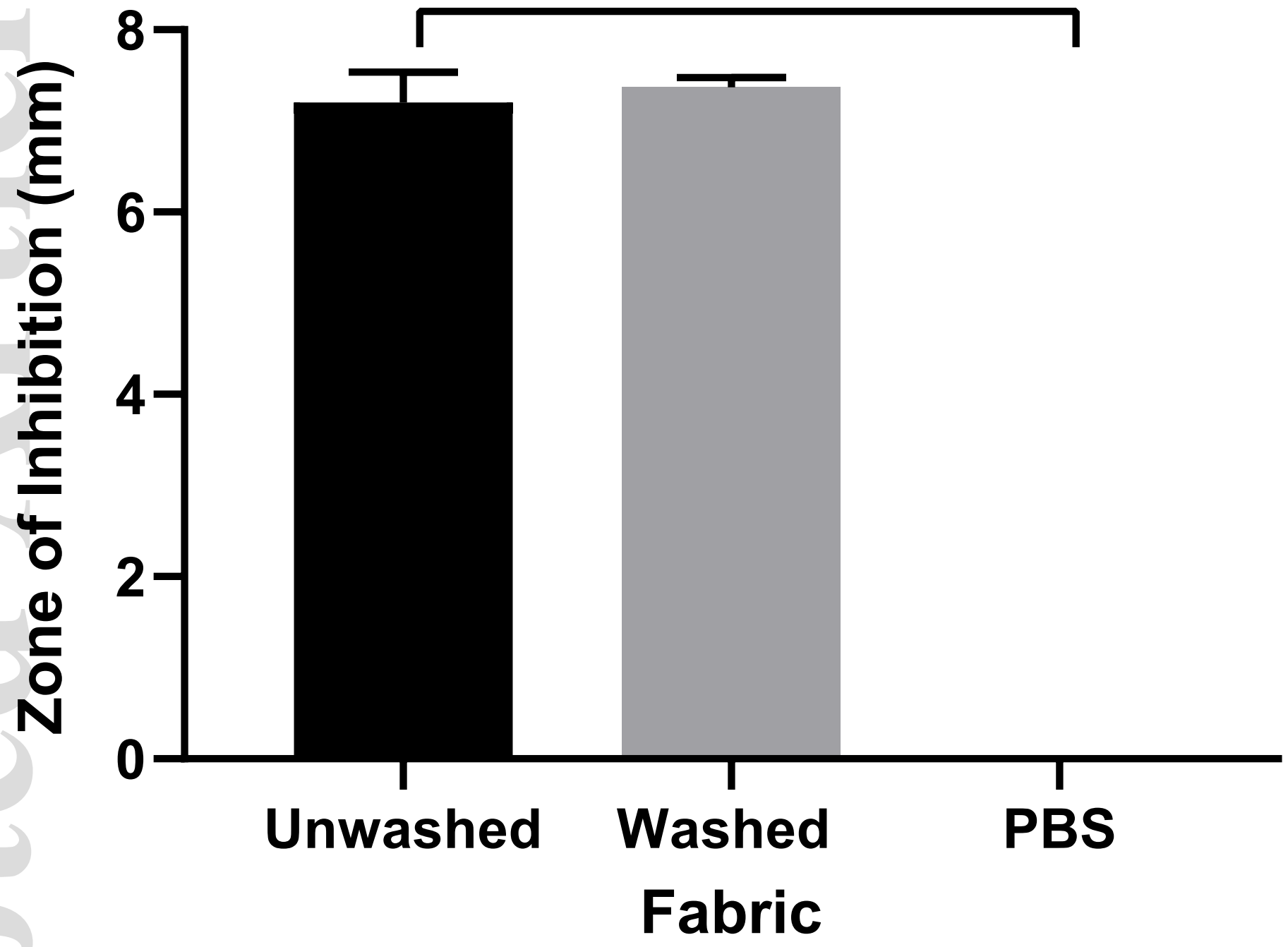

jam_14945_f4.eps 
$* * * *$

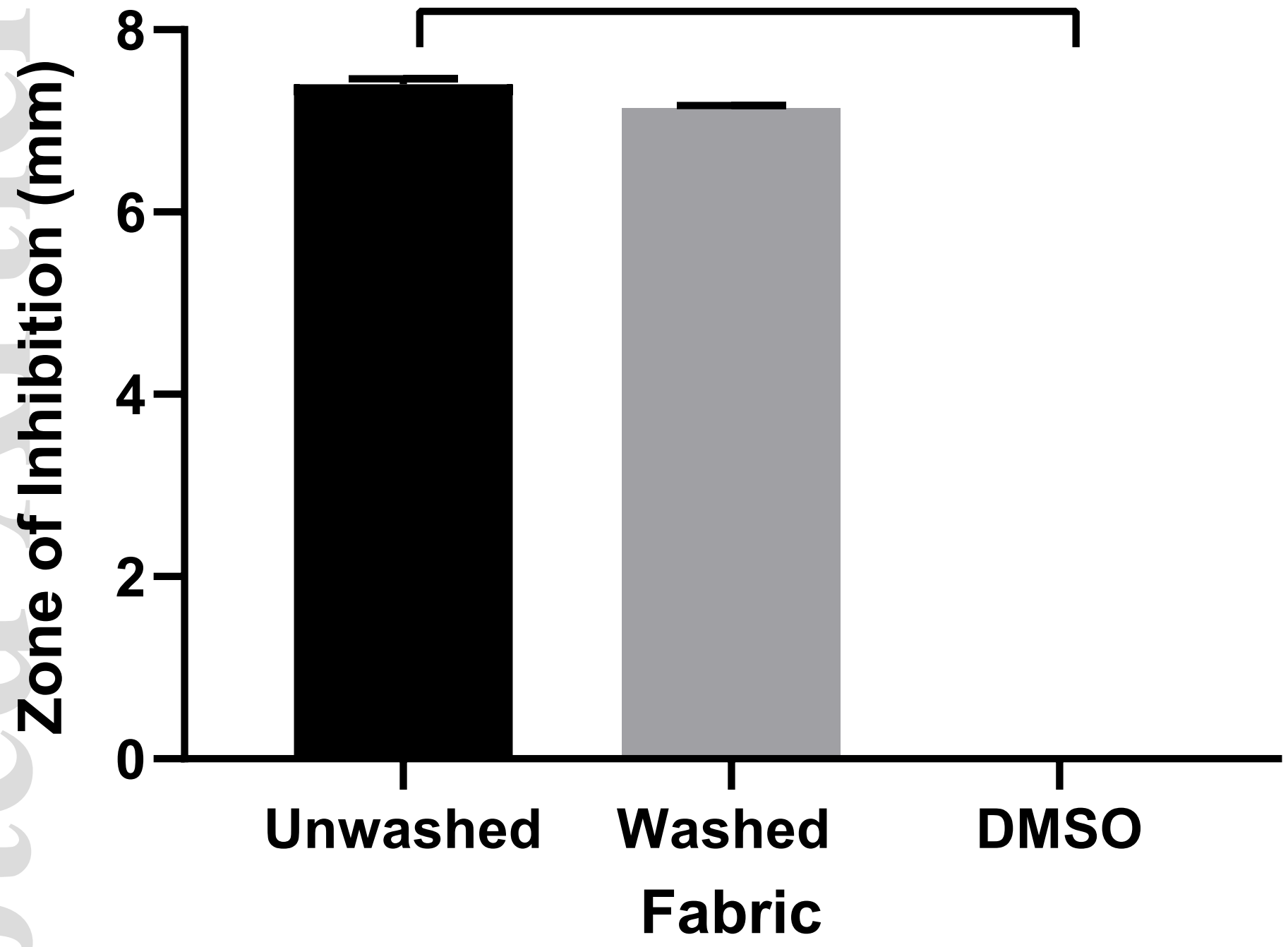

jam_14945_f5.eps 


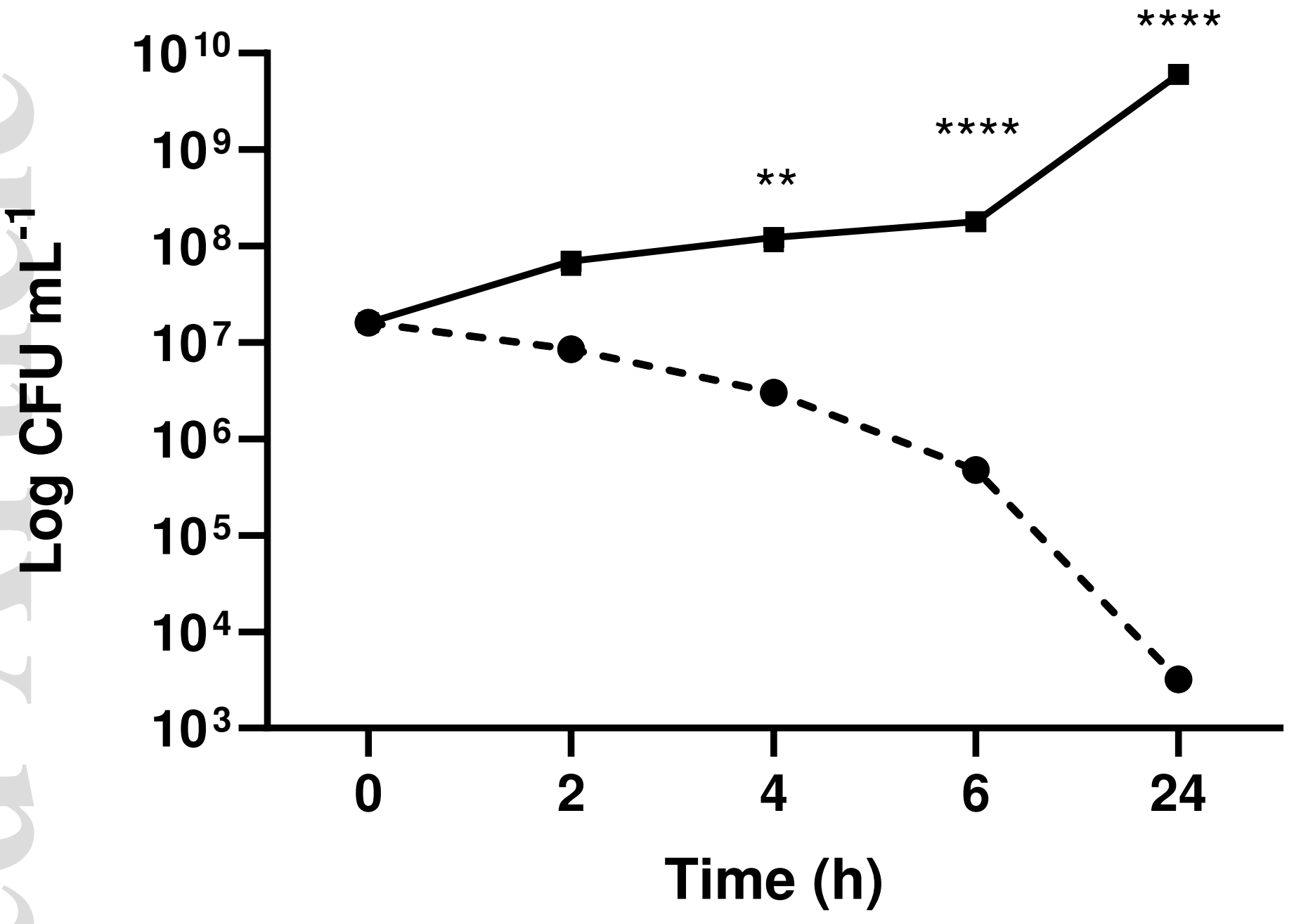

jam_14945_f6.eps 


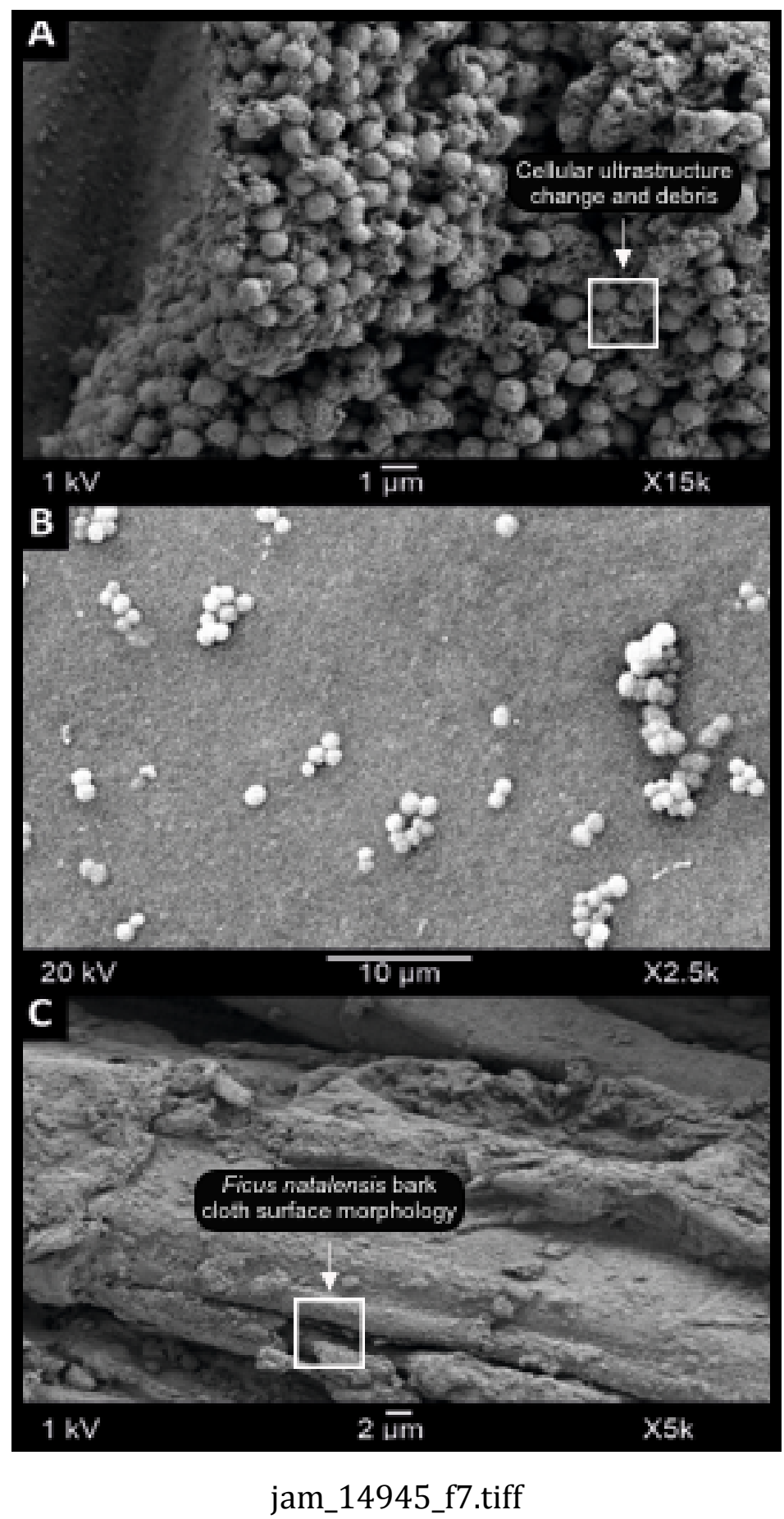

This article is protected by copyright. All rights reserved 